\title{
SISTEMA PRODUTO-SERVIÇO COMO ALTERNATIVA PARA INOVAÇÃO NO DESIGN DE EMBALAGENS
}

Eduardo Jorge T. G. Neves

Universidade Federal da Paraíba

Ej_jorge@hotmail.com

Angélica de Souza Galdino Acioly Universidade Federal da Paraíba angelicaufpb@gmail.com

Resumo: A prosperidade de uma economia pode ser medida através dos seus bens de consumo, e o capitalismo demonstra o sucesso através da abundância deles. O consumo muitas vezes é feito de forma inconsciente, e como já atestado, nossa "sociedade do consumo" gera uma quantidade gigantesca de lixo. Para Kazian (2005), uma sociedade pautada no Nimby (Not in my backyard), em tradução livre: "Não no meu quintal", reflexo de uma população que só vê a etapa final do seu próprio uso, no caso - o lixo. O pensamento comum do "jogar fora" e ilusoriamente acreditar que o resíduo descartado vai sumir, é muito prejudicial ao planeta. Segundo Parker (2015), mais de 8 milhões de toneladas de plástico acabaram nos oceanos, e esse número pode ser decuplicada nos próximos 10 anos, se continuarmos no ritmo atual. O uso de plástico para produtos de consumo se tornou dominante, e sua produção cresceu absurdamente desde que ele começou a ser usado em larga escala na metade do século passado. Em 2012, mais de 280 milhões de toneladas de plástico foram manufaturadas globalmente segundo a National Geographic (2015). Quando se trata das embalagens, que muitas vezes são de plástico, essa problemática é muito pertinente. Uma idéia que vem sendo adotada pelas indústrias e empresas, é a utilização de sistemas de refis, visando redução de material e consequentemente, reduzindo o que é descartado na natureza. Nestes termos, torna-se de extrema importância a geração contínua de alternativas de embalagens cada vez mais sustentáveis. Uma das estratégias para o desenvolvimento de produtos mais sustentáveis trata de um Sistema Produto Serviço (PSS). O PSS, segundo o Programa Ambiental das Nações Unidas (UNEP, 2002), refere-se a um sistema de inovação, que é resultado da mudança do pensamento apenas no produto físico, e de sua transição para a oferta de produtos e serviços que possa satisfazer a demandas específicas. Neste sentido, objetivo desta pesquisa é compreender de que forma um PSS pode ser aplicado no desenvolvimento de embalagens, a fim de sistematizar o ciclo de vida (Pré-Produção, Produção, Distribuição, Uso e Descarte). Para tanto, foi realizada uma pesquisa de natureza bibliográfica, através de um levantamento de artigos 2 científicos em congressos e periódicos, teses e dissertações, sites - 
nacionais e internacionais, relacionados à sustentabilidade, consumo e sociedade e ciclo de vida do produto. Os resultados prévios demonstram que o PSS tem sido usado de forma bem sucedida em serviços como aluguéis de carros e bicicletas, por exemplo. No caso da embalagem, sistemas como esse que envolvam o seu ciclo de vida, tem sido um campo de estudo em ascensão para o Design. A relevância desta pesquisa, em andamento, está na perspectiva de ampliar o arcabouço teórico/prático sobre esse tema para o desenvolvimento de embalagens com foco na sustentabilidade ambiental e econômica. Palavras-chave: Embalagens, Sistema produto-serviço, Sustentabilidade.

Palavras-chave: Embalagens; Sistema Produto Serviço; Sustentabilidade 